\title{
Community exposures to chemical incidents: development and evaluation of the first environmental public health surveillance system in Europe
}

\author{
H J Bowen, S R Palmer, H M P Fielder, G Coleman, P A Routledge, D L Fone
}

\begin{abstract}
Objective-To describe the frequency, nature and location of acute chemical incidents in Wales, and the morbidity in employees, emergency responders and the general public who were exposed.

Design-Active multi-agency communitybased surveillance system.

Setting-Wales, 1993-5.

Main outcome measures-Frequency, nature and location of incidents, populations potentially exposed and with symptoms.

Results-Most of the 402 incidents identified were not associated with sites governed by the Control of Industrial Major Accident Hazard Regulations but with smaller industrial sites and commercial premises. About two in every thousand of the estimated 236000 members of the public considered to be at risk from exposure reported symptoms, which were mainly nausea, headaches, and irritation of the eye, skin and respiratory tract. The most commonly reported chemicals that members of the public were exposed to were smoke toxins, miscellaneous organics, toxic gases and flammable gases. A health authority was reported to be involved in only $34(8 \%)$ of the incidents and in only 3 of the 29 incidents where more than 100 members of the public were exposed.

Conclusion-A geographically defined, multi-agency surveillance system can identify high risk locations and types of incidents, together with the chemicals most likely to be involved. Such ongoing surveillance information is essential for appropriate policy making, emergency planning, operational management and training.

(F Epidemiol Community Health 2000;54:870-873)
\end{abstract}

Centre for

Therapeutics and

Toxicology, University

of Wales College of

Medicine

P A Routledge

Gwent Health

Authority, Pontypool

D L Fone

Correspondence to:

Professor Palme

(palmersr@cf.ac.uk)

Accepted for publication 20 May 2000

With the increasing numbers of new chemicals entering the global market each year-between 200 and 1000 new chemicals with production capacities in excess of one tonne per annum ${ }^{1}$ - concern is growing about potential population health effects, particularly from accidental releases of chemicals such as occurred at Lowermoor, ${ }^{2}$ Bhopal $^{3}$ and Seveso. ${ }^{4}$ Public concern itself may result in perceived health effects, as in the Worcester water incident, ${ }^{5}$ but a recent study of the grounding of the Sea Empress oil tanker on the Pembro- keshire coast reported real physical health effects in the general population after controlling for anxiety. ${ }^{6}$ Despite these concerns the frequency, type and consequences of incidents in the United Kingdom has not been documented systematically. We report here the results of a population-based study that provided a model for an on-going chemical incident surveillance scheme for the UK.

\section{Method}

A chemical incident was defined pragmatically as any unforeseen event involving chemicals that causes ill health or that was considered by public health agencies to have the potential to cause ill health and that therefore necessitated an immediate response. Incidents that involved only occupational exposures within industrial premises were excluded from surveillance.

All 37 local authority environmental health departments, both port health authorities and one of the three fire brigades in Wales participated in a full three year study (19931995). In addition, daily press cuttings from the national Welsh newspapers were reviewed to identify incidents. The Welsh National Poisons Unit participated in 1994 and 1995.

Each agency received a monthly prompt to complete a specially designed reporting form for all incidents or to provide "nil returns". The variables collected were date; nature and location of incident; the source of initial notification; other agencies involved, the numbers exposed and with symptoms, chemicals released, and details of environmental monitoring and health surveillance undertaken. In most incidents actual numbers of people who were or who might be exposed could only be estimated roughly as biomarker surveys of exposure and dispersion modelling are seldom carried out. Therefore we have recorded the estimates made by local responders of the numbers of people at risk of exposure.

\section{Results}

Four hundred and thirty five reports about 402 incidents were received; 271 (67\%) from local authority environmental health departments (EHDs), 54 (13\%) from Gwent Fire Service, $84(21 \%)$ through the press cuttings and 26 (6\%) from the Welsh National Poisons Unit (WNPU). There was little overlap in incident reporting with $367(91 \%)$ incidents reported by a single agency. Only two incidents were reported by both the EHDs and the WNPU. Of the 90 incidents reported in the press, only 31 
Table 1 Number of incidents, reported by nature and location of incident

\begin{tabular}{|c|c|c|c|c|c|c|c|c|c|c|c|c|c|}
\hline Incident & $\begin{array}{l}\text { Operational } \\
\text { industrial }\end{array}$ & $\begin{array}{l}\text { Vacant } \\
\text { industrial }\end{array}$ & $\begin{array}{l}\text { Commercial } \\
\text { premises }\end{array}$ & $\begin{array}{l}\text { Agricultural } \\
\text { premises }\end{array}$ & $\begin{array}{l}\text { Residential } \\
\text { premises }\end{array}$ & $\begin{array}{l}\text { Waste } \\
\text { disposal } \\
\text { sites }\end{array}$ & Highway & $\begin{array}{l}\text { Coastal } \\
\text { waters }\end{array}$ & $\begin{array}{l}\text { Inland } \\
\text { waters }\end{array}$ & $\begin{array}{l}\text { Open } \\
\text { public } \\
\text { spaces }\end{array}$ & $\begin{array}{l}\text { Swimming } \\
\text { pools }\end{array}$ & Other* & Total \\
\hline Airborne release & 39 & 2 & 9 & 2 & 27 & 5 & 2 & 0 & 0 & 1 & 5 & 2 & 94 \\
\hline Chemical spill & 33 & 1 & 7 & 9 & 4 & 3 & 31 & 19 & 9 & 3 & 0 & 2 & 121 \\
\hline Fire & 40 & 4 & 2 & 2 & 0 & 0 & 1 & 1 & 0 & 1 & 0 & 0 & 51 \\
\hline Explosion & 6 & 0 & 2 & 0 & 0 & 0 & 1 & 1 & 0 & 0 & 0 & 0 & 10 \\
\hline Water contamination & 2 & 0 & 2 & 0 & 15 & 0 & 0 & 0 & 0 & 0 & 0 & 1 & 20 \\
\hline Waste deposit(s) & 1 & 6 & 1 & 1 & 3 & 2 & 10 & 13 & 3 & 16 & 0 & 0 & 56 \\
\hline Blue-green algae & 0 & 0 & 0 & 0 & 0 & 0 & 0 & 0 & 10 & 0 & 0 & 0 & 10 \\
\hline Other algae & 0 & 0 & 0 & 0 & 0 & 0 & 0 & 11 & 0 & 0 & 0 & 0 & 11 \\
\hline Other† & 5 & 2 & 3 & 3 & 3 & 0 & 1 & 0 & 0 & 2 & 0 & 10 & 29 \\
\hline Total & 126 & 15 & 26 & 17 & 52 & 10 & 46 & 45 & 22 & 23 & 5 & 15 & 402 \\
\hline
\end{tabular}

^Includes hospitals and educational establishments. †Includes food contamination incidents.

Table 2 Chemicals and chemical groups associated with incidents in Wales, 1993-1995*

\begin{tabular}{ll}
\hline Chemicals & Number \\
\hline Chemical, rubber, plastic, tyre and oil fires & 28 \\
Miscellaneous organics, including isocyanates & 17 \\
Harmful and toxic gases $\left(\mathrm{NH}_{3}, \mathrm{Cl}_{2}, \mathrm{Br}_{2}, \mathrm{H}_{2} \mathrm{~S}, \mathrm{CS}_{2}, \mathrm{HCN}, \mathrm{CO}\right)$ & 17 \\
Flammable gases (methane, butane, propane, natural gas) & 15 \\
Agrochemicals & 14 \\
Solvents, solvent-based products, resins & 14 \\
General fires & 14 \\
Detergents, cleaning agents and damp proofing agents & 13 \\
Particulates and fume & 13 \\
Oil & 12 \\
Asbestos & 10 \\
Blue-green algae & 10 \\
Sulphuric acid & 9 \\
Phosphorus / phosphoric acid & 9 \\
Other petroleum hydrocarbons, including diesel and paraffin & 7 \\
Metals (Na, Hg, Cd, Cu, Pb, Fe) & 7 \\
Hydrochloric acid & 7 \\
Alkali (potassium and sodium hydroxide) & 7 \\
Petrol & 6 \\
Freon refrigerant & 6 \\
Other acids (sodium hypochlorite, chromic and nitric acids) & 6 \\
Red algae & 5 \\
Metal contaminated soils & 5 \\
Miscellaneous (munitions, landfill leachate, surface coating products) & 5 \\
Miscellaneous inorganics & 5 \\
Brown algae (phaeocystis) & 4 \\
Landfill gases & 4 \\
Radioactive substances & 3 \\
\hline & \\
\hline
\end{tabular}

^Only those appearing in the database three or more times are listed.

were also reported by EHD. Of the 55 incidents reported by Gwent Fire, only six were reported by EHD. EHDs identified incidents mainly through calls made by members of the public $(43 \%)$ and by industry $(10 \%)$, the fire service $(13 \%)$, and the National Rivers Authority $(11 \%)$, whereas poisons unit incidents were mainly identified through accident and emergency departments (65\%). The Fire Service identified incidents mainly from industry $(30 \%)$, the police $(22 \%)$ and members of the public $(17 \%)$.

The most frequently reported types of incident were chemical spills $(30 \%)$, followed by airborne releases $(23 \%)$, exposures to waste materials (14\%) and chemical fires (13\%) (table 1). Incidents occurred most commonly at operational industrial sites (31\%), (but only 14 of these involved sites covered by the control of industrial major accident hazard (CIMAH) regulations), residential premises (13\%), on the highway $(11 \%)$ and in coastal waters $(11 \%)$. Details of the chemicals released were provided in $354(88 \%)$ of the 402 incidents. Seventy per cent $(n=249)$ involved the release of a single chemical. Smoke toxins, from chemical, rubber, plastic, tyre and oil fires $(n=28)$; miscellaneous organics $(n=17)$; toxic gases, such as ammonia and chlorine $(n=17)$; and flammable gases, such as methane and butane $(n=15)$ were the most commonly reported classes of chemicals released (table 2).

There were 204 incidents where an estimated 236000 members of the public were at risk of exposure. In 29 incidents more than 100 members of the public were estimated to have been exposed. The commonest exposures were to gaseous emissions (for example, carbon monoxide) in residential premises $(n=22)$, chemical spills (for example, acids) at operational industrial premises $(n=20)$ and on the highway $(n=10)$; spills of oils and sewage in coastal waters $(n=10)$, water contamination (for example, contamination with pesticides) in residential premises $(n=15)$ and waste deposits (for example, clinical waste and sodium hydroxide) in open public spaces $(n=12)$.

In 64 incidents members of the public reported symptoms, with a total of 575 people becoming ill.

Table 3 shows the most common categories of incidents causing symptoms to be reported. The symptoms most commonly experienced in incidents were nausea (23 incidents), headache (22 incidents), respiratory irritation (20 incidents), eye irritation (14 incidents) and skin or nose and throat irritation (10 incidents). Of all the 64 incidents where members of the public experienced symptoms, the WNPU reported eight and the EHDs reported 53. The Health Authority was involved in only 14 of these 64 incidents.

Table 3 Most frequently reported categories of incident in which members of the public reported symptoms

\begin{tabular}{lllll}
\hline $\begin{array}{l}\text { Number of } \\
\text { incidents (\%) }\end{array}$ & Type & Site & Chemical & $\begin{array}{l}\text { Number of } \\
\text { people } \\
\text { effected }\end{array}$ \\
\hline $17(27)$ & Gaseous emissions & Residential premises & Carbon monoxide & $\begin{array}{l}20 \\
\text { Damp proof course } \\
\end{array}$ \\
& & Industrial premises & Hydrogen sulphide and volatile organic compounds & 273 \\
$13(2)$ & Blue-green algae & Inland waters & Plant toxin & 8 \\
& Chemical spill & Highway & Hydrochloric acid & 14 \\
& & & Sodium hydroxide & \\
& & Trichloroethylene & \\
\hline
\end{tabular}


Emergency responders (fire, police and ambulance services) were exposed in 170 $(42 \%)$ of the 402 incidents. In only nine incidents were symptoms reported with 28 $(2 \%)$ of the 1514 responders affected. Twelve became ill after fires involving unspecified chemicals, industrial waxes and plastics, six had symptoms after work in a flood, three became ill after a release of wood preservative containing arsenic and copper, and one after a release of phenol fumes at a factory. Symptoms experienced were respiratory and eye irritation (four incidents) headache and throat irritation (three incidents), nausea (two incidents) and dizziness (one incident).

\section{Discussion}

The overall health impact of accidental chemical exposures is unknown, as national data have not been available in the UK. Responsibility for management and documentation of accidents varies with the type and location of the chemical exposures. Population-based surveillance could provide information to describe the hazards to enable public health services to be better prepared for such incidents and to manage them more effectively. ${ }^{7-11}$

The All Wales Environmental Health Surveillance Project is the first population-based surveillance system of acute chemical incidents to have been described in Europe, although a similar surveillance system has been operational in some States in the United States of America since $1990 .{ }^{12-14}$ We have shown the necessity for a multi-agency approach as there was little overlap in the incidents reported by the various participating agencies. The combined reports from the three participating agencies, together with press cuttings, indicated that on average 2.6 chemical incidents involving community exposures and requiring an immediate public health response occurred each week in Wales with a population of about 2.9 million.

We undertook active surveillance to improve the timeliness of returns, and all eligible participating agencies consistently reported incidents or "nil returns" on a monthly basis. However, the representativeness of the system and the quality of the health outcome data could be improved further. The results in Gwent, where 52 incidents were reported only by the Fire Service suggests that the sensitivity of the surveillance system would have been improved by the participation of all fire services, as well as of other agencies in Wales. Press cuttings were shown to be a useful source of data that uniquely identified 54 incidents.

Health Authorities have been required since 1993 to have plans in place to respond to public health aspects of chemical incidents. ${ }^{15}$ The need for public health doctors to have a central role in planning for, and managing chemical incidents is well recognised. ${ }^{16-18}$ However, in this project the health authorities were only involved in the management of 34 of the 402 incidents. At the time, the primary public health focus for emergency planning was the Control of Industrial Major Accident Hazard (CIMAH) Regulations, $1984,{ }^{19}$ recently

\section{KEY POINTS}

- Acute chemical incidents involving exposure of communities are common.

- Active, multi-agency systems are required for effective surveillance.

- Health authorities are often not aware of chemical incidents.

- National surveillance information is needed to develop evidence-based public health policy, emergency planning and training.

amended by implementation of the COMAH Directive. Only 14 incidents over the three years of the project were reported at CIMAH sites. Early consideration must therefore be given to the need to develop plans and guidelines for dealing with the public health risks that arise more commonly at other sites. ${ }^{20}$

The identification of high risk locations and types of incidents, together with the chemicals most likely to be involved will also be of use to persons involved in emergency planning, to assure the availability of appropriate expertise, equipment and medicines in the future. Listing the chemicals most frequently involved in incidents is already helping to prioritise the development of toxicological profiles for use by public health professionals in Wales and to develop training programmes for emergency responders and public or environmental health professionals.

This multi-agency system demonstrated how surveillance could improve planning and management for chemical incidents. National surveillance of chemical incidents for the whole of the United Kingdom has subsequently been developed, improving on the sensitivity of this system by the addition of more reporting agencies. We would anticipate that hypotheses generated from surveillance will lead to work on prevention of such incidents and protection of the public health. This system could provide the basis for other systems such as centralised reporting of major incidents. ${ }^{21}$

We wish to thank the officers of all local authority environmental health departments in Wales, as well as those of the Welsh National Poisons Unit and the former Gwent Fire Service for the submission of monthly surveillance reports. We are also grateful to the 12 members of the Steering Group, under the grateful to the $12 \mathrm{members}$ of the Steering Group, under the
chairmanship of $\mathrm{Mr}$ Ronnie Alexander, for their advice and chairmanship of $\mathrm{Mr}$ Ronnie Alexander, for their advice and
guidance in the development and maintenance of the project.

Funding: The All Wales Environmental Health Surveillance Project was jointly funded by grants from the Chief Medical Officer for Wales' Research Budget and the former Council of Welsh Districts (through the collection of annual subscriptions from local authority Environmental Health Departments in Wales).

Conflicts of interest: none.

1 Earthwatch, United Nations Environmental Programme. Chemical pollution: a global overview. Geneva: The International Register of Potentially Toxic Chemicals and The Global Environmental Monitoring and Assessment Research Centre, 1992:5.

2 Mayon-White RT. How should another Camelford be managed? BM7 1993;307:398-9.

3 Zaidi SH. Bhopal and after. Am f Ind Med 1986;9:215-16.

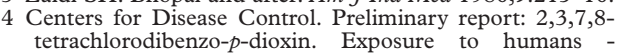
Seveso, Italy. Morb Mortal Wkly Rep 1988;37:733-6.

5 Fowle SE, Constantine CE, Fone DL, et al. An epidemioFowle SE, Constantine CE, Fone DL, et al. An epidemio-
logical study after a water contamination incident near logical study after a water contamination incident near
Worcester, England, in April 1994. F Epidemiol Community Worcester, England, in
Health 1995;50:18-23. 
6 Lyons RA, Temple JFT, Evans D, et al. Acute health effects of the Sea Empress oil spill. $\mathcal{F}$ Epidemiol Community Health of the Sea Empress

7 Ayres PJ. Major Chemical Incidents-a response, the role of the Consultant in Communicable Disease Control and the case of need for a national surveillance-resource centre. $\mathcal{F}$ Public Health Med 1995;17:164-70.

8 Hill PM, O'Sullivan DG. A study of arrangements for the identification and investigation of incidents of acute exposure of the public to toxic substances. London: Department of Health, 1992.

9 Philipp R. Surveillance systems and the role of a preventative medical team in chemical incidents. Occup Environ Med 1995;53:502-4.

10 Forbes GI. National Recording of Environmental Incidents in Scotland. F R Soc Health 1993;113:295-7.

11 Thacker SB, Stroup DF, Parrish RG, et al. Surveillance in environmental public health: issues, systems and sources. Am f Public Health 1996;86:633-8.

12 Binder S. Deaths, injuries and evacuations from acute hazardous materials releases. Am $\mathcal{f}$ Public Health 1989;79: ardous $1042-4$.

13 Agency for Toxic Substances and Disease Registry. Hazardous Substances Emergency Events Surveillance System (HSEESS) Annual Report 1995. Atlanta: US Department of Health and Human Sciences, Public Health Service, 1995.
14 Hall HI, Haugh GS, Price-Green PA, et al. Risk factors for hazardous substance releases that result in injuries and
evacuations: data from 9 states. Am 7 Public Health evacuations: data

15 NHS Management Executive. Health service guidelines. Arrangements to deal with health aspects of chemical contamination incidents - HSG (93)38. Heywood: NHSME, 1993.

16 Baxter PJ, Davies, PC, Murray,V. Medical planning for toxic releases into the community: the example of chlorine gas. British fournal of Industrial Medicine 1988;46:277-85.

17 Ayres PJ. Major chemical incidents-a response, the role of the consultant in communicable disease control and the case of need for a national surveillance-resource centre. $\mathcal{F}$ Public Health Med 1995;17:164-70.

18 Gunnell DJ. The public health physician's roles in chemical incidents. F Public Health Med 1993;15:352-7.

19 Health and Safety Executive. A guide to the control of industrial major accident hazards regulations 1984. London: HMSO, 1985.

20 IPCS and IOMC. Public health and chemical incidents. Cardiff: WHO Collaborating Centre for an International Clearing House for Major Chemical Incidents, 1999.

21 Carley S, Mackway-Jones K, Donnan S. Major incidents in Britain over the past 28 years: the reporting of major incidents. $\mathcal{F}$ Epidemiol Community Health 1998;52:392-8. 